\title{
学会のグローバル化について
}

\section{Promoting China-Japan Collaboration in the Field of Neurobiophysics

\author{
Jun-Xian SHEN
}

I have engaged in academic exchanges in the field of biophysics for about 30 years. In May 1985, the first ChinaJapan Bilateral Symposium on Biophysics held successfully in Wuxi, China, about 500 attendees. As an organizer, I have made the acquaintance of many famous scientists, including Setsuro Ebashi, Fumio Oosawa, Ei Teramoto, Sho Asakura, Michiki Kasai, Nobuhiro Go, Yoshimasa Kyogoku, Kuniaki Nagayama and so on. Subsequently, nine Symposia on Biophysics have held, e.g. C-J BSB (1988, 1991), EABS (1994, $1997,2000,2003,2006)$ and $\operatorname{ABA}(2009,2011)$. As a member of ABA Steering Committee (2011), I believe these meetings benefit all of us and present great opportunities to discuss interesting subjects with colleagues.

As an invited speaker, I was happy to attend the $17^{\text {th }}$ SEIRIKEN Conference under the title of "Frontiers in Optical Neurosciences" and "Comparative Neurophysiology" to honor Professor Akira Watanabe's life-long scientific achievements (March 1992). Later, as a visiting scholar, I was invited to work on optical recording of brain stem activity with Prof. Kohtaro Kamino in the Tokyo Medical and Dental University (1993) and on spatial hearing of bushcrickets with Dr. Makio Kashino in the NTT BRL (1997). In March 30 2010, IUPAB
Council meeting was held in Okazaki. As a delegate of BSC, I attended the meeting to report the progress of $17^{\text {th }}$ International Biophysics Congress (Oct.30-Nov.3 2011, Beijing). Fortunately, I visited again to the Natl. Inst. Physiol. Sci. (NIPS) almost 20 years passed. This tour to NIPS and previous visit to SEIRIKEN Brain Institute gave me extremely deep impression on achievements in the field of biophysics and neuroscience in Japan.

My major is neurobiophysics, specially animal acoustic communication and auditory mechanism in the brain. Recently I and my collaboration team demonstrated that males of concave-eared torrent frog Odorrana tormota living near fast-flowing streams possess ultrasonic communication capacity (Nature 2006). Ultrasonic perception in the frog species represents a new example of independent evolution. Before ovulation, gravid females emit high-frequency short calls that are distinct from males' advertisement calls. Playbacks of female calls evoke vocalizations and extraordinarily precise positive phonotaxis. The localization accuracy of O. tormota is remarkable in light of their small head size (interaural distance of $<1 \mathrm{~cm}$ ), and suggests an additional selective advantage of high-frequency hearing beyond the ability to avoid masking

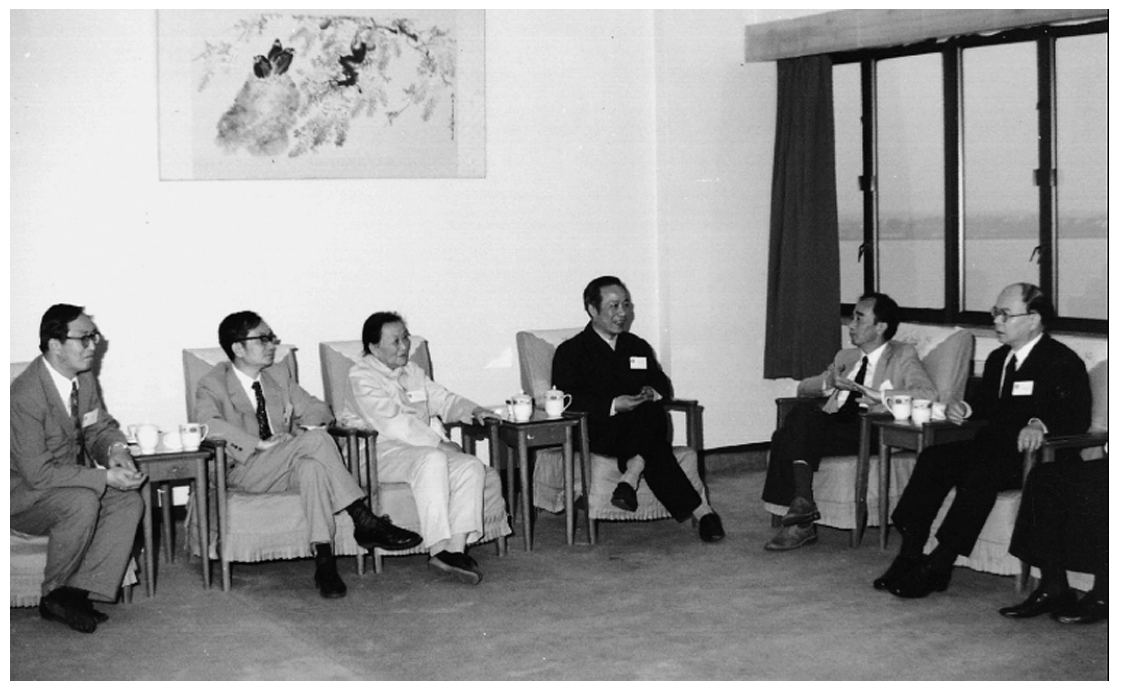

The first China-Japan Bilateral Symposium on Biophysics held successfully in May 1985, Wuxi China. The leaders from Biophysical Society of China and Biophysical Society of Japan (from left to right): Jun-Xian SHEN, Ke-Chun LIN, Shu-Min SHEN, Dong-Cai LIANG, Sho Asakura, Setsuro EBASHI. 


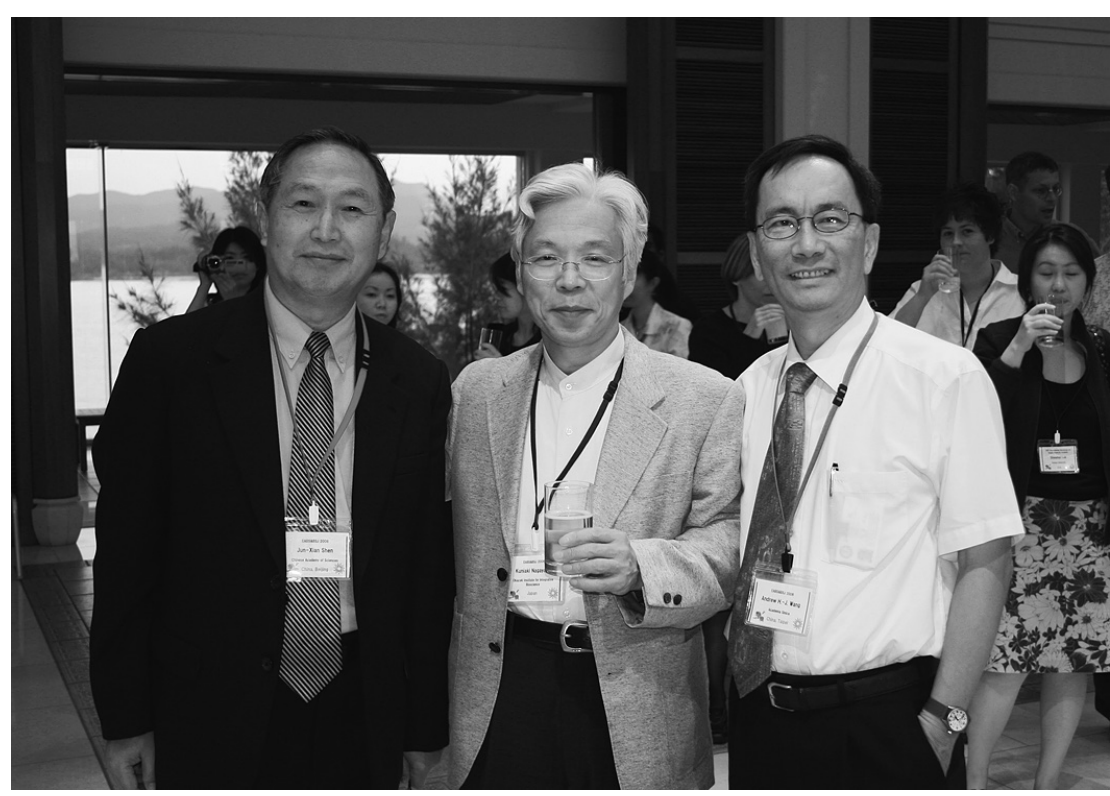

On a Steering Committee meeting of East Asian Biophysics Symposium (Okinawa 2006). From left to right: Jun-Xian SHEN, Kuniaki Nagayama, Adrew WANG.

by low-frequency background noise (Nature 2008). Furthermore, O. tormota can tune its ears dynamically by closing its normally open Eustachian tubes, resulting in an up to $20 \mathrm{~dB}$ gain in eardrum vibration at high frequencies $(10-32 \mathrm{kHz})$ and $26 \mathrm{~dB}$ attenuation at low frequencies $(3-10 \mathrm{kHz}$ ) (Proc. Natl. Acad. Sci. USA 2008). However, the females have no ear canals. Our combined studies have shown that there are noticeable sex differences in hearing between the sexes of O. tormota (Nature Communication 2011). All evidences imply the frog species $O$. tormota have evolved high-frequency sound communication system, although anatomical adapta- tions and neural mechanisms remain to be further investigated. I sincerely hope Japanese biophysicists and neurobiologists can collaborate with us to promote neurobiophysical researches in some interesting fields.

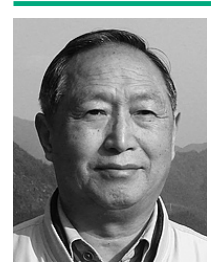

Jun-Xian SHEN

\section{Jun-Xian SHEN}

Institute of Biophysics, Chinese Academy of Sciences Vice-President of the Biophysical Society of China

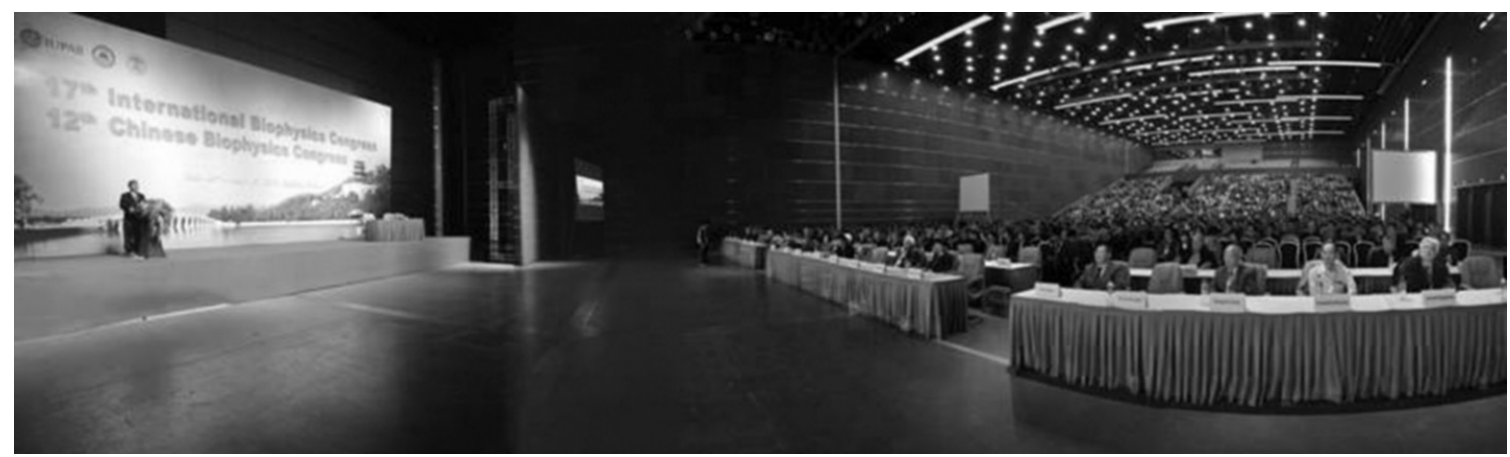

The opening ceremony for the 17th IUPAB Congress held in Beijing. The Congress took place in the Chinese National Convention Center from 30 October to 3 November 2011. 